\title{
Prevalence and subtype distribution of Blastocystis in ethnic minority groups on both sides of the China-Myanmar border, and assessment of risk factors
}

\author{
Baiyan Gong ${ }^{1}$, Xiaohua Liu ${ }^{1}$, Yanchen $\mathrm{Wu}^{1}$, Ning $\mathrm{Xu}^{2}$, Meng $\mathrm{Xu}^{2}$, Fengkun Yang ${ }^{1}$, Lei Tong ${ }^{1}$, Kexin Zhou ${ }^{1}$, \\ Jianping $\mathrm{Cao}^{2}$, Aiqin Liu, ${ }^{1, *}$, and Yujuan Shen ${ }^{2, *}$ \\ ${ }^{1}$ Department of Parasitology, Harbin Medical University, Harbin, 150081 Heilongiiang, PR China \\ ${ }^{2}$ National Institute of Parasitic Diseases, Chinese Center for Disease Control and Prevention, Chinese Center for Tropical Diseases \\ Research, WHO Collaborating Centre for Tropical Diseases, National Center for International Research on Tropical Diseases, Ministry \\ of Science and Technology, Key Laboratory of Parasite and Vector Biology, MOH, Shanghai 200025, PR China
}

Received 6 June 2019, Accepted 16 July 2019, Published online 25 July 2019

\begin{abstract}
Blastocystis is one of the most common intestinal parasites in humans worldwide. To understand its prevalence and to explore the risk factors for Blastocystis in humans in developing countries, a molecular epidemiological investigation of Blastocystis was conducted in ethnic minority groups on both sides of the China-Myanmar border. A total of 461 fecal specimens were collected from 289 Yao people in China and 172 Wa people in Myanmar, together with a questionnaire for each participant. Based on sequence analysis of the partial small subunit of ribosomal RNA (SSU rRNA) gene (barcode region or 260 bp region), an average prevalence of 6.29\% (29/461) was observed, with 4.50\% (13/289) in Yao people and 9.30\% (16/172) in Wa people. Twenty-two Blastocystis isolates were successfully subtyped by sequence analysis of the barcode region. Three subtypes were identified: ST1 $(n=7)$, ST3 $(n=13)$ and ST4 $(n=2)$. A statistical difference in the prevalence of Blastocystis was only observed between children $(12.37 \%$, $12 / 97)$ and adults $(4.95 \%, 16 / 323)$, and between not washing hands $(11.02 \%, 14 / 127)$ and washing hands $(4.76 \%$, $15 / 315$ ) after using toilets, emphasizing the importance and necessity of health education in people in the investigated areas, especially in children.
\end{abstract}

Key words: Blastocystis, humans, subtyping, risk factors, gastrointestinal symptoms.

\begin{abstract}
Résumé - Prévalence et distribution des sous-types de Blastocystis dans les groupes de minorités ethniques des deux côtés de la frontière Chine-Myanmar, et évaluation des facteurs de risque. Blastocystis est l'un des parasites intestinaux les plus répandus chez l'homme dans le monde. Pour comprendre la prévalence de Blastocystis et explorer les facteurs de risque chez l'homme dans les pays en développement, une enquête épidémiologique moléculaire sur Blastocystis a été menée auprès de groupes ethniques minoritaires des deux côtés de la frontière Chine-Myanmar. $\mathrm{Au}$ total, 461 spécimens fécaux ont été collectés auprès de 289 Yao en Chine et 172 Wa au Myanmar, accompagnés d'un questionnaire pour chaque participant. D'après l'analyse de la séquence du gène partiel de l'ARNr SSU (région du barcode ou région de $260 \mathrm{pb}$ ), une prévalence moyenne de 6,29\% (29/461) a été observée, dont 4,50 \% (13/289) chez les Yao et 9,30\% (16/172) chez les Wa. Vingt-deux isolats de Blastocystis ont été sous-typés avec succès par analyse de séquence de la région du barcode. Trois sous-types ont été identifiés : ST1 $(n=7)$, ST3 $(n=13)$ et ST4 $(n=2)$. Une différence statistique dans la prévalence de Blastocystis n'a été observée qu'entre les enfants $(12,37 \%, 12 / 97)$ et les adultes $(4,95 \%, 16 / 323)$ et entre le fait de ne pas se laver les mains $(11,02 \%, 14 / 127)$ et se laver les mains $(4,76 \%, 15 / 315)$ après avoir utilisé les toilettes, ce qui souligne l'importance et la nécessité de l'éducation à la santé chez les habitants des zones étudiées, en particulier les enfants.
\end{abstract}

\footnotetext{
*Corresponding authors: Iiuaiqin1128@126. com;
} amyshyj12@163.com

This is an Open Access article distributed under the terms of the Creative Commons Attribution License (http://creativecommons.org/licenses/by/4.0), which permits unrestricted use, distribution, and reproduction in any medium, provided the original work is properly cited. 


\section{Introduction}

Blastocystis is a common eukaryotic microorganism worldwide, living in the large intestine of humans and numerous animal hosts including insects and reptiles [1]. Humans can be infected via the fecal-oral pathway, mainly through ingesting water and food contaminated with Blastocystis cysts as well as close-contact with animals infected with Blastocystis [11]. The number of individuals infected by this parasite is estimated to have increased to more than one billion worldwide [2]. The prevalences reported vary according to geographical regions but are generally higher in developing countries $(22.1-100 \%)$ than in developed countries (0.5-23.1\%), which might be related to differences in hygiene standards, waste disposal, exposure to animals, and consumption of contaminated food or water [29, 35].

Currently, multiple methods have been used for the detection of Blastocystis. Common direct smear examination by light microscopic and in vitro culture does not seem to reflect the true prevalence of Blastocystis in fecal specimens due to the low sensitivity and specificity of the diagnostic techniques employed [40, 44]. Molecular diagnostic techniques have been widely used for accurate identification and subtyping of Blastocystis, and the small subunit of ribosomal RNA (SSU rRNA) gene has been a popular gene marker for diagnostic Polymerase chain reaction (PCR) assays [40]. PCR followed by restriction fragment length polymorphism (PCR-RFLP) results are difficult to compare when different numbers and types of restriction endonucleases are used, or when the PCR products are amplified using different primer pairs [38]. PCR employing subtype-specific sequence-tagged-site primers (STS PCR) has the limitation of detecting only seven known subtypes, ST1-ST7 [6]. However, sequence analysis of PCR-amplified SSU rRNA gene fragments has the ability to both identify the presence of Blastocystis and genetically characterize this organism. To date, at least 17 subtypes (ST) have been identified in mammals and birds [11]. Ten subtypes (ST1-ST9 and ST12) have been reported in humans, with nine (ST1-ST8 and ST12) being potentially zoonotic [8]. Four subtypes (ST1-ST4) show the highest frequency (more than 90\%) in human Blastocystis carriage, with a predominance of ST3 (around 60\% of these isolates) [5]. In contrast, the other subtypes (ST5-ST8), rarely identified in humans, are more commonly found in some animal hosts: ST5 in hoofed animals, ST6 and ST7 in birds, and ST8 in non-human primates [39]. ST12 has been found in giraffes, kangaroos, yaks, waterbuck, cattle, and goats [32].

The pathogenic role of Blastocystis is controversial because of the presence of Blastocystis in significant numbers in both symptomatic and asymptomatic individuals, and the inconsistency of clinical symptoms [21]. Some studies suggested that Blastocystis carriage was associated with gastrointestinal symptoms (including diarrhea, abdominal pain, bloating and flatulence), irritable bowel syndrome (IBS) and extra-intestinal disorders (including urticaria, iron deficiency anemia and chronic angioedema) [1]. However, some studies have shown that Blastocystis can be a commensal parasite in humans without any pathogenic effect [14], and even appears to be more common in healthy individuals than in individuals with IBS [23]. Additionally, other studies considered Blastocystis a common member of the intestinal flora in healthy individuals [33].
Recently, some studies reported occurrence of Blastocystis in ethnic minority groups. Risk factors related to Blastocystis were explored in Orang Asli (Aborigine) in Malaysia [3, 24]. In a study on the molecular characterization of Blastocystis conducted in the Indigenous Tapirapé ethnic group from the Brazilian Amazon Region, the subtype distribution was observed to be markedly different from that reported in Europe: ST4 was not detected and ST3 was not the most common subtype [20]. However, little information is available on Blastocystis carriage in Yao people and Wa people from both sides of the China-Myanmar border. To understand the prevalence and subtype distribution of Blastocystis in these ethnic minority groups, a cross-sectional investigation of Blastocystis was conducted in the present study by PCR and sequence analysis of the partial SSU rRNA gene. Additionally, possible risk factors for Blastocystis carriage were assessed.

\section{Materials and methods \\ Ethics statement}

The present study was reviewed and approved by the Ethics Committee of the National Institute of Parasitic Diseases, Chinese Center for Disease Control and Prevention, China, and Myanmar Eastern Shan State Special Region 2 Ethic Health Organization. All participants were informed of the study objectives and the procedures involved in study participation at enrollment. Written informed consent was obtained from all adult participants before collection of fecal specimens. Additionally, for the individuals under 18 years of age, written consent was obtained from their guardians.

\section{Specimen collection}

During the period between April and October 2018, a crosssectional investigation of Blastocystis was carried out in seven villages in two study sites on both sides of the China-Myanmar border. Approximately 5-10 g of fresh fecal specimens were collected from 461 people (one each). In all, 62.69\% (289/ 461) of specimens were from Yao people (aged 21-72 years) in three villages of the Yao Ethnic Township in Mengla County of Xishuangbanna Dai Autonomous Prefecture, Yunnan Province, China $\left(101.33^{\circ} \mathrm{E}\right.$ and $\left.21.27{ }^{\circ} \mathrm{N}\right)$. Similarly, $37.31 \%$ (172/461) of specimens were from Wa people (aged 7-53 years) in four villages in Pangkham, a main town of Pangsang Township of Matman District, Shan State, Myanmar $\left(99.11^{\circ} \mathrm{E}\right.$ and $22.10^{\circ} \mathrm{N}$ ). At the time of sampling, diarrheal specimens were noted to have loose or liquid stools by macroscopic observation, whereas the remaining had normal consistency and color. All the specimens were delivered to the laboratory in a cooler with ice packs within $24 \mathrm{~h}$ after collection and stored in a freezer at $-20{ }^{\circ} \mathrm{C}$ before DNA extraction.

\section{Questionnaire}

A structured questionnaire was administered to each study participant by health professionals from the local Center for Disease Control and Prevention (CDC). The questionnaire 
contained some information on socio-demographic characteristics, personal hygiene habits, and other possible risk factors for Blastocystis carriage as well as common gastrointestinal symptoms (diarrhea, nausea, emesis, abdominal pain and anorexia) (S1 Questionnaire). Meanwhile, each questionnaire was linked to one fecal specimen and used for our analysis in the present study.

\section{DNA extraction}

Genomic DNA was directly extracted from approximately 180-200 mg of each of fecal specimen using a QIAamp DNA Stool Mini Kit (QIAgen, Hilden, Germany), according to manufacturer-recommended procedures and the provided reagents. Meanwhile, to obtain a high yield of DNA, the lysis temperature was increased to $95{ }^{\circ} \mathrm{C}$. DNA was eluted in $200 \mu \mathrm{L}$ of $\mathrm{AE}$ and stored at $-20{ }^{\circ} \mathrm{C}$ prior to use in molecular analysis.

\section{PCR amplification}

All DNA preparations were identified and subtyped for Blastocystis by amplifying a $600 \mathrm{bp}$ nucleotide fragment (barcode region) of the SSU rRNA gene of Blastocystis [34]. To increase the detection rate of Blastocystis, all negative DNA preparations in the barcode region were subsequently subjected to PCR amplification of a nucleotide fragment of approximately $260 \mathrm{bp}$ within the barcode region, an amplicon that only allows detection of the parasite [22]. The primers and the cycling parameters were used as described previously by Menounos et al. [22] and Scicluna et al. [34].

TaKaRa Taq DNA polymerase (TaKaRa Bio Inc., Tokyo, Japan) was used for all PCR reactions. A negative control without DNA and a positive control (DNA of Blastocystis ST10 derived from a sika deer) were used in all PCR tests. Each DNA preparation was analyzed at least twice by PCR. All PCR products were subjected to electrophoresis in a $1.5 \%$ agarose gel and visualized by staining the gel with GelStrain (TransGen Biotech., Beijing, China).

\section{Nucleotide sequencing and analyzing}

All the positive PCR products of expected size were directly sequenced with their respective PCR primers on an ABI PRISM ${ }^{\mathrm{TM}} 3730$ DNA Analyzer by Sinogeno-max Biotechnology Co., Ltd. (Beijing, China), using a BigDye Terminator v3.1 Cycle Sequencing kit (Applied Biosystems, Foster City, CA, USA). Sequence accuracy was confirmed by twodirectional sequencing and by sequencing two additional PCR products for some DNA preparations, which produced the sequences different from those published in GenBank databases. Nucleotide sequences obtained in the present study were compared to all Blastocystis homologous sequences published in GenBank using BLAST searches (http://www.ncbi.nlm.nih. gov/blast/). They were then aligned and analyzed with each other and reference sequences downloaded from the GenBank database using the program Clustal X 1.83 (http://www. clustal.org/) to determine the presence and subtypes of
Blastocystis. Blastocystis subtypes were identified by determining the exact match or the closest similarity according to the proposed standard of Blastocystis terminology [38].

Two novel nucleotide sequences obtained in the present study were deposited in the GenBank database under the following accession numbers: MK898939 and MK898940.

\section{Statistical analyses}

Statistical analyses (Pearson chi-square test or Fisher's exact test) were performed using the Statistical Package for the Social Sciences (SPSS) 19.0 to assess possible risk factors for Blastocystis carriage (Table 1), and to determine the relationship between Blastocystis carriage and gastrointestinal symptoms (Table 2), respectively. A $p$ value of $<0.05$ was considered statistically significant.

\section{Results}

\section{Prevalence of Blastocystis and possible risk factors}

A total of 37 DNA preparations were successfully amplified and sequenced in either of the barcode regions and the $260 \mathrm{bp}$ region of the SSU rRNA gene. Based on sequence analysis, 29 DNA preparations were confirmed to be positive for Blastocystis (Fig. 1). An average prevalence of $6.29 \%$ (29/461) was observed in the investigated people on both sides of the China-Myanmar border, with $4.50 \%$ (13/289) in Yao people in China and $9.30 \%(16 / 172)$ in Wa people in Myanmar. Blastocystis was found in all seven villages, with the prevalence ranging from $3.23 \%$ to $15.63 \%$ (Table 3 ).

In the present study, all 461 participants were asked to fill out questionnaires. However, 19 participants provided incomplete information except gender, age and gastrointestinal symptoms. In the end, 442 completed questionnaires were used for assessment of possible risk factors for Blastocystis carriage. The prevalences of Blastocystis were statistically different in two categories of possible risk factors: children $(12.37 \%$, $12 / 97)$ versus adults $(4.95 \%, 16 / 323)$, and not washing hands after using toilets $(11.02 \%, 14 / 127)$ versus washing hands after using toilets $(4.76 \%, 15 / 315)$ (Table 1$)$.

\section{Blastocystis subtypes and homology analysis}

Twenty-two of 29 DNA preparations positive for Blastocystis were successfully subtyped by sequence analysis of the barcode region. Three subtypes were identified: ST1 $(n=7)$, ST3 $(n=13)$ and ST4 $(n=2)$ (Fig. 1). ST3 was the most common in people in the investigated areas $(59.09 \%, 13 / 22)$. Three subtypes could be seen in both Yao people and Wa people (Table 3).

By homology analysis of the barcode region of 22 Blastocystis isolates, eight representative sequences were obtained, with three, three and two from ST1, ST3 and ST4 isolates, respectively. Among them, the two sequences identified as ST3 (MK898939) and ST4 (MK898940) were not described previously, but had the largest similarity with those in humans 
Table 1. Assessment of possible risk factors for Blastocystis carriage.

\begin{tabular}{|c|c|c|c|}
\hline Variable & No. positive/No. examined ${ }^{\mathrm{b}}(\%)$ & OR $(95 \% \mathrm{CI})^{\mathrm{c}}$ & $\chi^{2 / p \text { value }}$ \\
\hline \multicolumn{4}{|l|}{ Gender } \\
\hline Male & $12 / 247(4.86)$ & $0.59(0.28,1.27)$ & $1.85 / 0.17$ \\
\hline Female & $17 / 214(7.94)$ & & \\
\hline \multicolumn{4}{|l|}{ Age (years) } \\
\hline Children (7-12) & $12 / 97(12.37)$ & Ref & \\
\hline Teenagers $(13-17)$ & $1 / 41(2.44)$ & $5.65(0.71,44.95)$ & $2.27 / 0.13$ \\
\hline Adults $(\geq 18)$ & $16 / 323(4.95)$ & $0.37(0.17,0.81)$ & 6.60/0.01 ${ }^{\mathrm{d}}$ \\
\hline \multicolumn{4}{|l|}{ Drinking boiled water } \\
\hline Yes & $25 / 393(6.36)$ & $1.31(0.44,3.93)$ & $0.03 / 0.86$ \\
\hline No & $4 / 49(8.16)$ & & \\
\hline \multicolumn{4}{|l|}{ Washing hands before meals } \\
\hline Yes & $17 / 322(5.28)$ & $1.99(0.92,4.31)$ & $3.18 / 0.08$ \\
\hline No & $12 / 120(10.00)$ & & \\
\hline \multicolumn{4}{|l|}{ Washing hands after using toilets } \\
\hline Yes & $15 / 315(4.76)$ & $2.48(1.16,5.30)$ & $5.79 / 0.02^{\mathrm{d}}$ \\
\hline No & $14 / 127(11.02)$ & & \\
\hline \multicolumn{4}{|c|}{ Eating unwashed vegetables and fruits } \\
\hline Yes & $25 / 381(6.56)$ & $1.00(0.34,2.98)$ & $0 / 1.00$ \\
\hline No & $4 / 61(6.56)$ & & \\
\hline \multicolumn{4}{|l|}{ Swimming ${ }^{a}$} \\
\hline Yes & $2 / 40(5.00)$ & $1.37(0.31,5.98)$ & $0.01 / 0.93$ \\
\hline No & $27 / 402(6.72)$ & & \\
\hline \multicolumn{4}{|l|}{ Pit toilets } \\
\hline Public & $25 / 364(6.87)$ & $1.36(0.46,4.04)$ & $0.10 / 0.76$ \\
\hline Individual & $4 / 78(5.13)$ & & \\
\hline \multicolumn{4}{|l|}{ Animal feeding patterns } \\
\hline Free-ranging & $6 / 86(6.98)$ & $1.52(0.41,5.74)$ & $0.07 / 0.79$ \\
\hline Both free-ranging and captive & $19 / 317(5.99)$ & $0.56(0.18,1.73)$ & $0.46 / 0.50$ \\
\hline Captive & $4 / 39(10.26)$ & Ref & \\
\hline
\end{tabular}

${ }^{\text {a }}$ Ponds are the only swimming places in the investigated areas.

${ }^{\mathrm{b}}$ Only 442 participants provided complete information (other than gender and age).

${ }^{\mathrm{c}} \mathrm{CI}$, confidence interval.

${ }^{\mathrm{d}}$ Bold type for values indicates statistical significance.

Table 2. Relationship between Blastocystis carriage and gastrointestinal symptoms.

\begin{tabular}{lcccccc}
\hline Group & \multicolumn{5}{c}{ No. positive/No. examined (\%) } \\
\cline { 2 - 6 } & Gastrointestinal symptoms & Diarrhea & Abdominal pain & Nausea & Emesis & Anorexia \\
\hline Blastocystis-positive & $6 / 29(20.69)$ & $6 / 29(20.69)$ & $2 / 29(6.90)$ & $0 / 29$ & $0 / 29$ & $0 / 29$ \\
Blastocystis-negative & $92 / 432(21.30)$ & $79 / 432(18.29)$ & $38 / 432(8.80)$ & $7 / 432(1.62)$ & $12 / 432(2.78)$ & $10 / 432(2.31)$ \\
OR (95\% CI) & $0.96(0.38,2.44)$ & $1.17(0.46,2.96)$ & $0.77(0.18,3.36)$ & $1.02(1.00,1.03)$ & $1.03(1.01,1.05)$ & $1.02(1.00,1.04)$ \\
$\chi^{2} / p$ value & $0.01 / 0.94$ & $0.10 / 0.75$ & $0 / 0.99$ & $-/ 1.00^{\mathrm{b}}$ & $-/ 1.00^{\mathrm{b}}$ & $-/ 1.00^{\mathrm{b}}$ \\
\hline
\end{tabular}

${ }^{\text {a }}$ Indicating people who had at least one of the five symptoms listed in the present study.

${ }^{\mathrm{b}}$ Fisher's exact test.

from Iran (MG011638) and Germany (AY244620), respectively.

Among the remaining six sequences, two have only been reported in humans previously, and four have also been identified previously in animals, along with humans. One ST1 sequence showed $100 \%$ identity with those in animals, including a goat from the UK (MF186699) and an orang-utan from Japan (AB107967). Another two ST1 sequences were identical to those in a brown rat from the Czech Republic (MH021854) and a pig from the Philippines (KY610167), respectively. One ST3 sequence shared $100 \%$ sequence identity with those in animals, including a pig from the Philippines (KY610169) and
Japan (AB107963), a cow from Japan (AB107965) and a macaque from the Philippines (KY929101) (Table 3).

\section{Relationship between Blastocystis carriage and gastrointestinal symptoms}

All 461 questionnaires were used for assessment of the relationship between Blastocystis carriage and gastrointestinal symptoms. No statistical relationship was observed between them, accounting for $6.34 \%(23 / 363)$ and $6.12 \%(6 / 98)$ in asymptomatic and symptomatic individuals, respectively (Table 2). 


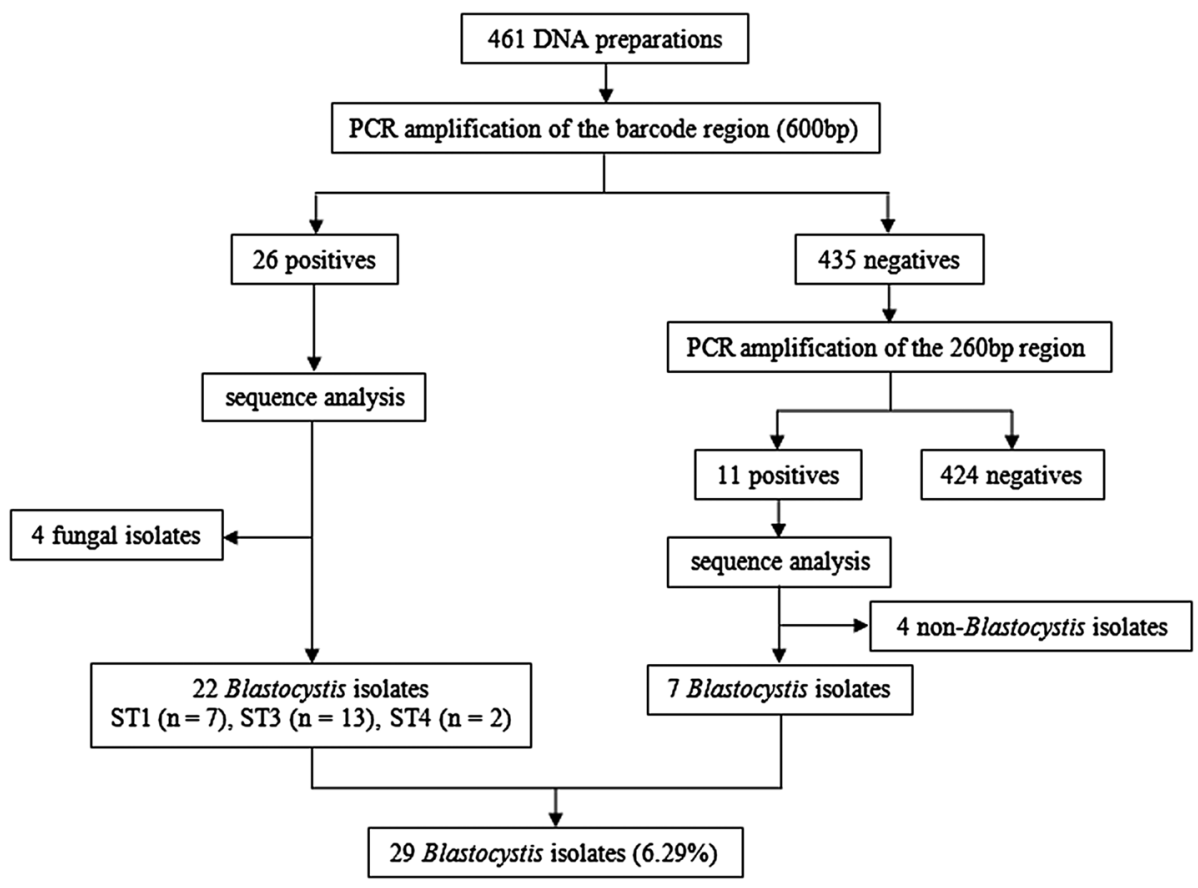

Figure 1. Flow diagram of prevalence and subtype identification of Blastocystis.

\section{Discussion}

Blastocystis has been reported in humans worldwide. In the present study, $4.50 \%$ (13/289) of Yao people in China and $9.30 \%$ (16/172) of Wa people in Myanmar were confirmed to be infected with Blastocystis.

The prevalence of Blastocystis is reported to be related to multiple factors. The immune status of hosts seems to be one main risk factor for Blastocystis carriage [47]. Immunodeficient/immunocompromized populations are more susceptible to Blastocystis carriage and its associated symptoms, showing opportunistic pathogenesis [40]. Kurniawan et al reported a high prevalence $(72.4 \%)$ of Blastocystis in HIV/AIDS patients presenting with diarrhea in Jakarta, Indonesia [15]. The present low prevalence of Blastocystis might be related to the large percentage $(70.07 \%, 323 / 461)$ of specimens from immunocompetent adults. Diagnostic methods also affect the prevalence estimates of Blastocystis. PCR-based molecular methods are observed to be superior to non-molecular methods in sensitivity and specificity [38]. In North Cyprus, the prevalence of Blastocystis was found to be $10.5 \%, 10.5 \%$, and $27.8 \%$ in humans by direct microscopy, trichrome method, and PCR, respectively [35]. In another study conducted in school-aged children (age 12-54 months) in Colombia, the prevalence of Blastocystis was $25.19 \%$ by microscopy and $39.22 \%$ by qPCR [42]. In addition, poor hygiene habits possibly increase the opportunity of Blastocystis carriage. A cross-sectional survey of Blastocystis in Malaysia discovered by multivariate analysis that drinking untreated water and the presence of other family members infected with Blastocystis were significant risk factors among three Orang Asli tribes and the overall population studied [3]. However, in the present study, a statistical difference in the prevalence of Blastocystis was observed between children $(12.37 \%, 12 / 97)$ and adults $(4.95 \%, 16 / 323)$, and between not washing hands after using toilets $(11.02 \%, 14 / 127)$ and washing hands after using toilets $(4.76 \%, 15 / 315)$. Like other intestinal parasites, not washing before eating and after using the toilet as well as sucking their fingers for some children favors Blastocystis by fecal-oral transmission.

Current molecular epidemiological data have revealed that ST1-ST4 account for more than 90\% of human cases of Blastocystis infection [8]. ST1 and ST3 are highly prevalent in Australia, Europe, and South Eastern Asia, while ST1 and ST2 are prevalent in America, and ST4 in Europe [36]. In recent studies from South America, ST1-ST3 were detected as the most frequent $[30,31]$. However, ST3 was not the most common subtype in the Indigenous Tapirapé ethnic group in Brazil, which was considered to be related to little contact between indigenous groups and people in other communities [20]. In the present study, three subtypes (ST1, ST3 and ST4) were identified in two ethnic groups, and ST3 was the most common in Yao people $(8 / 12,66.67 \%)$ and in Wa people $(5 / 10,50 \%)$, which was similar to findings previously reported in almost all the studies in China (Table 4) [18, 19, 41, 49, 50, 53-57], and in some studies in a nearby country (Thailand) $[25,28,37$, 52]. Minor subtypes (ST5-ST9 and ST12) that are only very rarely found in humans also show differences in geographical distribution. ST6 and ST7 are common in Asia but rarely observed in European countries, and ST5, ST8, ST9 and ST12 are found occasionally in humans [30, 47]. This being the first subtyping report of Blastocystis in Myanmar, the constitution and ratio of Blastocystis subtypes in this country needs to be assessed in the future by systematic molecular epidemiological investigations in larger populations from more areas.

In fact, difference in constitutions and ratios of Blastocystis subtypes might be related to different epidemiological characteristics, i.e., reservoirs and routes of transmission. Blastocystis has been found in various animals. The risk of zoonotic trans- 
Table 3. Prevalence and subtype distribution of Blastocystis in humans.

\begin{tabular}{|c|c|c|c|c|}
\hline \multirow[t]{2}{*}{ Location } & \multirow{2}{*}{$\begin{array}{c}\text { No. positive/ } \\
\text { No. examined (\%) }\end{array}$} & \multirow[t]{2}{*}{ Subtype $(n)^{\mathrm{a}}$} & \multicolumn{2}{|r|}{ GenBank ID ${ }^{\mathrm{b}}$} \\
\hline & & & Human & Animal (species) \\
\hline \multicolumn{5}{|c|}{ Yunnan, China } \\
\hline \multirow[t]{2}{*}{ Village 1} & $3 / 93(3.23)$ & ST3 (2) & KY610153 & $\begin{array}{l}\text { AB107963 (Pig); AB107965 (Cattle); } \\
\text { KY929101 (Macaque) }\end{array}$ \\
\hline & & Unknown (1) & & \\
\hline \multirow[t]{3}{*}{ Village 2} & $4 / 110(3.64)$ & ST1 (1) & MH349749 & MF186699 (Goat); AB107967 (Orang-utan) \\
\hline & & ST3 (1) & MF184939 & \\
\hline & & ST3 (2) & KY610153 & $\begin{array}{l}\text { AB107963 (Pig); AB107965 (Cattle); } \\
\text { KY929101 (Macaque) }\end{array}$ \\
\hline \multirow[t]{5}{*}{ Village 3} & $6 / 86(6.98)$ & ST1 (1) & MF184949 & MH021854 (Brown rat) \\
\hline & & ST1 (1) & KY610125 & KY610167 (Pig) \\
\hline & & ST3 (2) & MF184939 & \\
\hline & & ST3 (1) & MK898939 & \\
\hline & & ST4 (1) & MK898940 & \\
\hline Subtotal & $13 / 289(4.50)$ & $\begin{array}{l}\text { ST1 (3), ST3 (8), } \\
\text { ST4 (1), Unknown (1) }\end{array}$ & & \\
\hline \multicolumn{5}{|c|}{ Shan, Myanmar } \\
\hline \multirow[t]{3}{*}{ Village 4} & $5 / 32(15.63)$ & ST1 (3) & MH349749 & MF186699 (Goat); AB107967 (Orang-utan) \\
\hline & & ST3 (1) & MF184939 & \\
\hline & & Unknown (1) & & \\
\hline \multirow[t]{3}{*}{ Village 5} & $4 / 52(7.69)$ & ST3 (1) & KY610153 & $\begin{array}{l}\text { AB107963 (Pig); AB107965 (Cattle); } \\
\text { KY929101 (Macaque) }\end{array}$ \\
\hline & & ST4 (1) & MH197686 & \\
\hline & & Unknown (2) & & \\
\hline \multirow[t]{3}{*}{ Village 6} & $4 / 52(7.69)$ & ST1 (1) & МH349749 & MF186699 (Goat); AB107967 (Orang-utan) \\
\hline & & ST3 (1) & KY610153 & $\begin{array}{l}\text { AB107963 (Pig); AB107965 (Cattle); } \\
\text { KY929101 (Macaque) }\end{array}$ \\
\hline & & Unknown (2) & & \\
\hline Village 7 & $3 / 36(8.33)$ & ST3 (2) & KY610153 & $\begin{array}{l}\text { AB107963 (Pig); AB107965 (Cattle); } \\
\text { KY929101 (Macaque) }\end{array}$ \\
\hline Subtotal & $16 / 172(9.30)$ & $\begin{array}{c}\text { Unknown ST (1) } \\
\text { ST1 (4), ST3 (5), } \\
\text { ST4 (1), Unknown (6) }\end{array}$ & & \\
\hline Total & 29/461 (6.29) & $\begin{array}{c}\text { ST1 (7), ST3 (13), } \\
\text { ST4 (2), Unknown (7) }\end{array}$ & & \\
\hline
\end{tabular}

${ }^{\text {a }}$ Unknown indicates preparations in which DNA was only amplified and sequenced successfully in approximately 260 bp region of the SSU rRNA gene of Blastocystis.

${ }^{\mathrm{b}}$ Accession No. indicating the sequences downloaded from GenBank, which have $100 \%$ homology with the sequences obtained in the present study except two novel sequences (highlighted in bold) obtained here.

mission of Blastocystis has also been predicted by some previous studies. The same subtypes have been found in animals and their close contacts: ST1 and ST2 in zoo keepers and one wombat and five primate species in Australia [26]; ST2 in children and monkeys in Nepal [51]; ST5 in piggery workers and pigs in Australia [46]; ST6 in breeders and cattle/goats in Nepal $[16,17]$ and in slaughterhouse staff members and chickens in Lebanon [9]. Three subtypes (ST1, ST3 and ST4) of Blastocystis obtained in the present study have also been found in various animals, with ST1 in non-human primates (apes and baboons), monkeys, cattle, pigs, sheep, goats, foxes, dogs, and birds; ST3 in non-human primates, pigs, cattle, sheep, goats and racoon dogs; ST4 in rodents, rabbits, foxes, giraffes, kangaroos, dogs, a snow leopard, ostriches as well as non-human primates (ringtailed lemurs, woolly monkeys and siamangs) [36, 44, 45]. More importantly, some ST1 and ST3 sequences obtained in the present study were identical to those from animals (Table 3), implying a possibility of zoonotic transmission of Blastocystis. However, due to the lack of data of Blastocystis in local animals, the epidemiologic role of animals in the spread of Blastocystis remains unclear. It is necessary in the future to collect animal fecal specimens to test this assumption, especially common domestic pigs, dogs and chickens kept near houses. If these animals are infected with Blastocystis, they increase the opportunity of human carriage; meanwhile, animal feces can enter streams and rivers through surface run-off after heavy rain, which causes water contamination downstream and wide geographical spread. To the best of our knowledge, two waterborne outbreaks of blastocystosis have been documented worldwide [10, 48]. A total of 1122 people were involved in one outbreak in China, highlighting the importance of Blastocystis in public health [48].

Blastocystis has been reported to give rise to gastrointestinal symptoms, like diarrhea, abdominal pain, flatulence, nausea, 
Table 4. Prevalence and subtype distribution of Blastocystis in humans by province in China.

\begin{tabular}{|c|c|c|c|c|c|c|c|c|c|c|c|c|c|c|c|}
\hline \multirow[t]{2}{*}{ Province } & \multirow{2}{*}{$\begin{array}{l}\text { No. positive/No. } \\
\text { examined (\%) }\end{array}$} & \multicolumn{13}{|c|}{ Subtype $(\%)^{\mathrm{c}}$} & \multirow[t]{2}{*}{ Refs. } \\
\hline & & ST1 & ST2 & ST3 & ST4 & ST5 & ST6 & ST7 & ST12 & ST1 +2 & $\mathrm{ST} 1+3$ & $\mathrm{ST} 2+3$ & ST3 + 5 & Unknown $^{c}$ & \\
\hline Shanghai & $29 / 1505$ (1.93) & $6(20.7)$ & $1(3.4)$ & $17(58.7)$ & - & - & $1(3.4)$ & - & - & - & $2(6.9)$ & - & - & $2(6.9)$ & {$[18]$} \\
\hline Zhejiang & $10 / 170(5.88)$ & $3(30.0)$ & $1(10.0)$ & $6(60.0)$ & - & - & - & - & - & - & - & - & - & - & {$[18]$} \\
\hline \multirow[t]{2}{*}{ Jiangxi } & $35^{\mathrm{a}}$ & $13(37.1)$ & $2(5.7)$ & $14(40.0)$ & - & - & - & - & - & - & $5(14.3)$ & - & - & $1(2.9)$ & [49] \\
\hline & $3^{\mathrm{a}}$ & - & - & - & - & $2(66.7)$ & - & - & - & - & - & - & $1(33.3)$ & - & [50] \\
\hline \multirow[t]{3}{*}{ Guangxi } & $1^{\mathrm{a}, \mathrm{b}}$ & - & - & $1(100)$ & - & - & - & - & - & - & - & - & - & - & [53] \\
\hline & $10^{\mathrm{a}}$ & $8(80.0)$ & - & - & - & - & - & - & - & - & - & - & - & $2(20.0)$ & [54] \\
\hline & $53^{\mathrm{a}}$ & $4(7.6)$ & - & $17(32.1)$ & $4(7.5)$ & - & $1(1.9)$ & $5(9.4)$ & - & - & - & - & - & $22(41.5)$ & [55] \\
\hline \multirow[t]{5}{*}{ Yunnan } & $58 / 1440(4.03)^{\mathrm{b}}$ & $57(98.3)$ & $1(1.7)$ & - & - & - & - & - & - & - & - & - & - & - & [56] \\
\hline & $12 / 324(3.70)^{\mathrm{b}}$ & $3(25.0)$ & - & $2(16.7)$ & $3(25.0)$ & - & - & $3(25.0)$ & $1(8.3)$ & - & - & - & - & - & [41] \\
\hline & $153 / 646(23.68)$ & $38(24.8)$ & $7(4.5)$ & $93(60.8)$ & $1(0.7)$ & - & - & - & - & $1(0.7)$ & $6(3.9)$ & $1(0.7)$ & - & $6(3.9)$ & [18] \\
\hline & $78 / 239$ (32.64) & $16(20.5)$ & $1(1.3)$ & $55(70.5)$ & $1(1.3)$ & - & - & - & - & $1(1.3)$ & $1(1.3)$ & - & - & $3(3.8)$ & [19] \\
\hline & $13 / 289(4.50)$ & $3(23.1)$ & - & $8(61.5)$ & $1(7.7)$ & - & - & - & - & - & - & - & - & $1(7.7)^{\mathrm{d}}$ & This study \\
\hline Heilongjiang & $27 / 381(7.09)^{b}$ & $12(44.4)$ & - & $15(55.6)$ & - & - & - & - & - & - & - & - & - & - & [57] \\
\hline Total & & $160(34.1)$ & $13(2.8)$ & $220(47.0)$ & $9(1.9)$ & $2(0.4)$ & $2(0.4)$ & $8(1.7)$ & $1(0.2)$ & $2(0.4)$ & $14(3.0)$ & $1(0.2)$ & $1(0.2)$ & $36(7.7)$ & \\
\hline
\end{tabular}

-: negative results.

${ }^{a}$ Only Blastocystis isolates were subtyped in some studies.

${ }^{b}$ These Blastocystis isolates were identified and subtyped by PCR and sequencing, while others were subtyped by STS PCR.

${ }^{\mathrm{c}}$ Unknown subtypes of Blastocystis appearing in some studies were subtyped by STS PCR.

d This DNA preparation was only amplified and sequenced successfully in approximately 260 bp of the SSU rRNA gene of Blastocystis. 
vomiting, constipation, weight loss or fatigue, and in addition, there is an association between Blastocystis and IBS as well as urticaria [36]. However, Blastocystis carriage is also frequently detected in asymptomatic individuals, implying a nonpathogenic effect [14]. In the present study, no associations were observed between Blastocystis carriage and gastrointestinal symptoms as well as each symptom category. Currently, no consensus has been reached over the pathogenicity of Blastocystis. Even though Blastocystis shows pathogenicity in some studies, besides immune status of individuals, the occurrence and the severity of clinical symptoms are also observed to be related to the density of this pathogen in the intestinal tract as well as the virulence of subtypes [21, 40]. In a study conducted in Egypt, higher densities of Blastocystis were found in symptomatic patients than in asymptomatic ones with a statistically significant difference $(8.2$ cells vs. 3.8 cells $/ 100 \times$ field), and the mean number of Blastocystis was significantly higher in patients with diarrhea and abdominal pain [7]. Some studies have suggested a relationship between clinical symptoms and Blastocystis subtypes: STs 1, 2, 4 and 6 for gastrointestinal symptoms [4, 13]; ST2 for gastrointestinal symptoms and chronic urticaria [43]; and STs 1, 3 and 7 for IBS [12, 27]. In the present study, since $24.14 \%$ (7/29) of Blastocystis isolates were not successfully subtyped, the relationship between gastrointestinal symptoms and Blastocystis subtypes was not assessed.

\section{Conclusions}

The present study described the occurrence of Blastocystis in ethnic minority groups on both sides of the China-Myanmar border. Like in other intestinal protozoan infections including Giardia intestinalis and Entamoeba histolytica, young age and not washing hands after using toilets were two risk factors for Blastocystis carriage in the investigated areas, emphasizing the importance and necessity of health education among local people, especially children. Although no association was observed between Blastocystis carriage and gastrointestinal symptoms here, the pathogenic potential of Blastocystis cannot be excluded.

\section{Conflict of interest}

The authors declare that they have no conflicts of interest.

Acknowledgements. This work was supported partially by the National Science and Technology Major Project (No. 2018ZX10713001-004), and Chinese Special Program for Scientific Research of Public Health (No. 201502021). We thank the staff at the department of helminths, Yunnan Institute of Parasitic Diseases and the Center for Disease Control and Prevention, Mengla County of Xishuangbanna Dai Autonomous Prefecture, Yunnan Province, for their assistance with sample collection and case investigation.

\section{Supplementary material}

Supplementary material is available at https://www.parasite-journal.org/10.1051/parasite/2019046/olm

S1: Questionnaire.

\section{References}

1. Alinaghizade A, Mirjalali H, Mohebali M, Stensvold CR, Rezaeian M. 2017. Inter- and intra-subtype variation of Blastocystis subtypes isolated from diarrheic and non-diarrheic patients in Iran. Infection, Genetics and Evolution, 50, 77-82.

2. Andersen LO, Stensvold CR. 2016. Blastocystis in health and disease: Are we moving from a clinical to a public health perspective? Journal of Clinical Microbiology, 54, 524-528.

3. Anuar TS, Ghani MK, Azreen SN, Salleh FM, Moktar N. 2013. Blastocystis infection in Malaysia: evidence of waterborne and human-to-human transmissions among the Proto-Malay, Negrito and Senoi tribes of Orang Asli. Parasites \& Vectors, 6, 40.

4. Cakir F, Cicek M, Yildirim IH. 2019. Determination the subtypes of Blastocystis sp. and evaluate the effect of these subtypes on pathogenicity. Acta Parasitologica, 64, 7-12.

5. Cian A, El Safadi D, Osman M, Moriniere R, Gantois N, Benamrouz-Vanneste S, Delgado-Viscogliosi P, Guyot K, Li LL, Monchy S, Noël C, Poirier P, Nourrisson C, Wawrzyniak I, Delbac F, Bosc S, Chabé M, Petit T, Certad G, Viscogliosi E. 2017. Molecular epidemiology of Blastocystis sp. in various animal groups from two French zoos and evaluation of potential zoonotic risk. PLoS One, 12, e0169659.

6. Clark CG, van der Giezen M, Alfellani MA, Stensvold CR. 2013. Recent developments in Blastocystis research. Advances in Parasitology, 82, 1-32.

7. El-Shazly AM, Abdel-Magied AA, El-Beshbishi SN, El-Nahas HA, Fouad MA, Monib MS. 2005. Blastocystis hominis among symptomatic and asymptomatic individuals in Talkha Center, Dakahlia Governorate, Egypt. Journal of the Egyptian Society of Parasitology, 35, 653-666.

8. Forsell J, Bengtsson-Palme J, Angelin M, Johansson A, Evengård B, Granlund M. 2017. The relation between Blastocystis and the intestinal microbiota in Swedish travellers. BMC Microbiology, 17, 231.

9. Greige S, El Safadi D, Bécu N, Gantois N, Pereira B, Chabé M, Benamrouz-Vanneste S, Certad G, El Hage R, Chemaly M, Hamze M, Viscogliosi E. 2018. Prevalence and subtype distribution of Blastocystis sp. isolates from poultry in Lebanon and evidence of zoonotic potential. Parasites \& Vectors, 11, 389.

10. Guglielmetti P, Cellesi C, Figura N, Rossolini A. 1989. Family outbreak of Blastocystis hominis associated gastroenteritis. Lancet, 2, 1394.

11. Javanmard E, Niyyati M, Ghasemi E, Mirjalali H, Asadzadeh Aghdaei H, Zali MR. 2018. Impacts of human development index and climate conditions on prevalence of Blastocystis: a systematic review and meta-analysis. Acta Tropica, 185, 193203.

12. Jimenez-Gonzalez DE, Martinez-Flores WA, Reyes-Gordillo J, Ramirez-Miranda ME, Arroyo-Escalante S, Romero-Valdovinos M, Stark D, Souza-Saldivar V, Martinez-Hernandez F, Flisser A, Olivo-Diaz A, Maravilla P. 2012. Blastocystis infection is associated with irritable bowel syndrome in a Mexican patient population. Parasitology Research, 110, 12691275.

13. Kaneda Y, Horiki N, Cheng X, Tachibana H, Tsutsumi Y. 2000. Serologic response to Blastocystis hominis infection in asymptomatic individuals. Tokai Journal of Experimental and Clinical Medicine, 25, 51-56.

14. Khademvatan S, Masjedizadeh R, Rahim F, Mahbodfar H, Salehi R, Yousefi-Razin E, Foroutan M. 2017. Blastocystis and irritable bowel syndrome: frequency and subtypes from Iranian patients. Parasitology International, 66, 142-145. 
15. Kurniawan A, Karyadi T, Dwintasari SW, Sari IP, Yunihastuti E, Djauzi S, Smith HV. 2009. Intestinal parasitic infections in HIV/AIDS patients presenting with diarrhoea in Jakarta, Indonesia. Transactions of the Royal Society of Tropical Medicine and Hygiene, 103, 892-898.

16. Lee LI, Chye TT, Karmacharya BM, Govind SK. 2012. Blastocystis sp.: waterborne zoonotic organism, a possibility? Parasites \& Vectors, 5, 130.

17. Lee IL, Tan TC, Tan PC, Nanthiney DR, Biraj MK, Surendra KM, Suresh KG. 2012. Predominance of Blastocystis sp. subtype 4 in rural communities, Nepal. Parasitology Research, $110,1553-1562$.

18. Li LH, Zhang XP, Lv S, Zhang L, Yoshikawa H, Wu Z, Steinmann P, Utzinger J, Tong XM, Chen SH, Zhou XN. 2007. Cross-sectional surveys and subtype classification of human Blastocystis isolates from four epidemiological settings in China. Parasitology Research, 102, 83-90.

19. Li LH, Zhou XN, Du ZW, Wang XZ, Wang LB, Jiang JY, Yoshikawa H, Steinmann P, Utzinger J, Wu Z, Chen JX, Chen SH, Zhang L. 2007. Molecular epidemiology of human Blastocystis in a village in Yunnan province, China. Parasitology International, 56, 281-286.

20. Malheiros AF, Stensvold CR, Clark CG, Braga GB, Shaw JJ. 2011. Short report: Molecular characterization of Blastocystis obtained from members of the indigenous Tapirapé ethnic group from the Brazilian Amazon region, Brazil. American Journal of Tropical Medicine and Hygiene, 85, 1050-1053.

21. Matiut DS, Hritcu L. 2014. The pathogenic role of Blastocystis isolated from patients with irritable bowel syndrome and colitis from Iasi, Romania. Acta Parasitologica, 60, 116-123.

22. Menounos PG, Spanakos G, Tegos N, Vassalos CM, Papadopoulou C, Vakalis NC. 2008. Direct detection of Blastocystis sp. in human faecal samples and subtype assignment using single strand conformational polymorphism and sequencing. Molecular and Cellular Probes, 22, 24-29.

23. Mohamed RT, El-Bali MA, Mohamed AA, Abdel-Fatah MA, El-Malky MA, Mowafy NM, Zaghlool DA, Bakri RA, AlHarthi SA. 2017. Subtyping of Blastocystis sp. isolated from symptomatic and asymptomatic individuals in Makkah, Saudi Arabia. Parasites \& Vectors, 10, 174.

24. Mohammad NA, Al-Mekhlafi HM, Moktar N, Anuar TS. 2017. Prevalence and risk factors of Blastocystis infection among underprivileged communities in rural Malaysia. Asian Pacific Journal of Tropical Medicine, 10, 491-497.

25. Palasuwan A, Palasuwan D, Mahittikorn A, Chiabchalard R, Combes V, Popruk S. 2016. Subtype distribution of Blastocystis in communities along the Chao Phraya River, Thailand. Korean Journal of Parasitology, 54, 455-460.

26. Parkar U, Traub RJ, Vitali S, Elliot A, Levecke B, Robertson I, Geurden T, Steele J, Drake B, Thompson RC. 2010. Molecular characterization of Blastocystis isolates from zoo animals and their animal-keepers. Veterinary Parasitology, 169, 8-17.

27. Poirier P, Wawrzyniak I, Vivarès CP, Delbac F, El Alaoui H. 2012. New insights into Blastocystis spp.: a potential link with irritable bowel syndrome. PLoS Pathogens, 8, e1002545.

28. Popruk S, Udonsom R, Koompapong K, Mahittikorn A, Kusolsuk T, Ruangsittichai J, Palasuwan A. 2015. Subtype distribution of Blastocystis in Thai-Myanmar border, Thailand. Korean Journal of Parasitology, 53, 13-19.

29. Ramírez JD, Sánchez LV, Bautista DC, Corredor AF, Flórez AC, Stensvold CR. 2014. Blastocystis subtypes detected in humans and animals from Colombia. Infection, Genetics and Evolution, 22, 223-228.

30. Ramírez JD, Sánchez A, Hernández C, Flórez C, Bernal MC, Giraldo JC, Reyes P, López MC, García L, Cooper PJ, Vicuña Y, Mongi F, Casero RD. 2016. Geographic distribution of human Blastocystis subtypes in South America. Infection, Genetics and Evolution, 41, 32-35.

31. Ramírez JD, Flórez C, Olivera M, Bernal MC, Giraldo JC. 2017. Blastocystis subtyping and its association with intestinal parasites in children from different geographical regions of Colombia. PLoS One, 12, e0172586.

32. Ren M, Song JK, Yang F, Zou M, Wang PX, Wang D, Zhang HJ, Zhao GH, Lin Q. 2019. First genotyping of Blastocystis in yaks from Qinghai Province, northwestern China. Parasites \& Vectors, 12, 171.

33. Scanlan PD, Stensvold CR, Rajilić-Stojanović M, Heilig HG, De Vos WM, O'Toole PW, Cotter PD. 2014. The microbial eukaryote Blastocystis is a prevalent and diverse member of the healthy human gut microbiota. FEMS Microbiology Ecology, 90, 326-330.

34. Scicluna SM, Tawari B, Clark CG. 2006. DNA barcoding of Blastocystis. Protist, 157, 77-85.

35. Seyer A, Karasartova D, Ruh E, Güreser AS, Turgal E, Imir T, Taylan-Ozkan A. 2017. Epidemiology and prevalence of Blastocystis spp. in North Cyprus. American Journal of Tropical Medicine and Hygiene, 96, 1164-1170.

36. Skotarczak B. 2018. Genetic diversity and pathogenicity of Blastocystis. Annals of Agricultural and Environmental Medicine, 25, 411-416.

37. Srichaipon N, Nuchprayoon S, Charuchaibovorn S, Sukkapan P, Sanprasert V. 2019. A simple genotyping method for rapid differentiation of Blastocystis subtypes and subtype distribution of Blastocystis spp. in Thailand. Pathogens, 8, pii: E38.

38. Stensvold CR, Suresh GK, Tan KS, Thompson RC, Traub RJ, Viscogliosi E, Yoshikawa H, Clark CG. 2007. Terminology for Blastocystis subtypes-a consensus. Trends in Parasitology, 23, 93-96.

39. Stensvold CR, Clark CG. 2016. Current status of Blastocystis: a personal view. Parasitology International, 65, 763-771.

40. Tan KS. 2008. New insights on classification, identification, and clinical relevance of Blastocystis spp. Clinical Microbiology Reviews, 21, 639-665.

41. Teng XJ, Chu YH, Zhai CC, Yu YF, Cai YC, Chen SH, Ai L, Tian LG, Chen JX. 2018. The epidemiological characteristics and influencing factors for Blastocystis hominis infection among human immunodeficiency virus seropositive individuals in Tengchong of Yunnan Province. Chinese Journal of Parasitology and Parasitic Diseases, 36, 129-134 [in Chinese].

42. Villamizar X, Higuera A, Herrera G, Vasquez-A LR, Buitron L, Muñoz LM, Gonzalez-C FE, Lopez MC, Giraldo JC, Ramírez JD. 2019. Molecular and descriptive epidemiology of intestinal protozoan parasites of children and their pets in Cauca, Colombia: a cross-sectional study. BMC Infectious Diseases, $19,190$.

43. Vogelberg C, Stensvold CR, Monecke S, Ditzen A, Stopsack K, Heinrich-Gräfe U, Pöhlmann C. 2010. Blastocystis sp. subtype 2 detection during recurrence of gastrointestinal and urticarial symptoms. Parasitology International, 59, 469-471.

44. Wang J, Gong B, Yang F, Zhang W, Zheng Y, Liu A. 2018a. Subtype distribution and genetic characterizations of Blastocystis in pigs, cattle, sheep and goats in northeastern China's Heilongjiang Province. Infection, Genetics and Evolution, 57, 171-176.

45. Wang J, Gong B, Liu X, Zhao W, Bu T, Zhang W, Liu A, Yang F. 2018b. Distribution and genetic diversity of Blastocystis subtypes in various mammal and bird species in northeastern China. Parasites \& Vectors, 11, 522.

46. Wang $\mathrm{W}$, Owen $\mathrm{H}$, Traub RJ, Cuttell L, Inpankaew $\mathrm{T}$, Bielefeldt-Ohmann H. 2014. Molecular epidemiology of Blastocystis in pigs and their in-contact humans in Southeast 
Queensland, Australia, and Cambodia. Veterinary Parasitology, 203, 264-269.

47. Wawrzyniak I, Poirier P, Viscogliosi E, Dionigia M, Texier C, Delbac F, Alaoui HE. 2013. Blastocystis, an unrecognized parasite: an overview of pathogenesis and diagnosis. Therapeutic Advances in Infectious Disease, 1, 167-178.

48. Wu GH, Xiong YS, Cao GL, Li GM, Liu MZ, Zhu JL. 2000. Investigation of an epidemic outbreak of blastocystosis. Chinese Journal of Parasitic Disease Control, 13, 25-27 [in Chinese].

49. Yan Y, Su S, Lai R, Liao H, Ye J, Li X, Luo X, Chen G. 2006. Genetic variability of Blastocystis hominis isolates in China. Parasitology Research, 99, 597-601.

50. Yan Y, Su S, Ye J, Lai X, Lai R, Liao H, Chen G, Zhang R, Hou Z, Luo X. 2007. Blastocystis sp. subtype 5: a possibly zoonotic genotype. Parasitology Research, 101, 1527-1532.

51. Yoshikawa H, Wu Z, Pandey K, Pandey BD, Sherchand JB, Yanagi T, Kanbara H. 2009. Molecular characterization of Blastocystis isolates from children and rhesus monkeys in Kathmandu, Nepal. Veterinary Parasitology, 160, 295-300.

52. Yowang A, Tsaousis AD, Chumphonsuk T, Thongsin N, Kullawong N, Popluechai S, Gentekaki E. 2018. High diversity of Blastocystis subtypes isolated from asymptomatic adults living in Chiang Rai, Thailand. Infection, Genetics and Evolution, 65, 270-275.

53. Yu Y, Wu XP, Chu YH. 2015. A case of Blastocystis hominis (subtype 3) infection confirmed by PCR and in vitro culture. Chinese Journal of Parasitology and Parasitic Diseases, 33, 23 [in Chinese].

54. Zhan TZ, Shi HH, He SS, Liu T. 2012. Genotype analysis and isoenzyme patterns of ten isolates of Blastocystis hominis from Guangxi. Chinese Journal of Parasitology and Parasitic Diseases, 30, 36-40 [in Chinese].

55. Zhan TZ, Liu T, Shi HH, He SS, Yan H, Liu DY. 2014. PCRbased genotype classification of Blastocystis hominis isolates from college students of Guangxi. Chinese Journal of Parasitology and Parasitic Diseases, 32, 209-211 [in Chinese].

56. Zhang SX, Tian LG, Lu Y, Li LH, Chen JX, Zhou XN. 2016. Epidemiological characteristics of Blastocystis hominis in urban region, southwestern China. Chinese Journal of Zoonoses, 32, 424-428 [in Chinese].

57. Zhang W, Ren G, Zhao W, Yang Z, Shen Y, Sun Y, Liu A, Cao J. 2017. Genotyping of Enterocytozoon bieneusi and subtyping of Blastocystis in cancer patients: relationship to diarrhea and assessment of zoonotic transmission. Frontiers in Microbiology, $8,1835$.

Cite this article as: Gong B, Liu X, Wu Y, Xu N, Xu M, Yang F, Tong L, Zhou K, Cao J, Liu A \& Shen Y. 2019. Prevalence and subtype distribution of Blastocystis in ethnic minority groups on both sides of the China-Myanmar border, and assessment of risk factors. Parasite 26, 46 .

\section{O PARASTE}

An international open-access, peer-reviewed, online journal publishing high quality papers on all aspects of human and animal parasitology

Reviews, articles and short notes may be submitted. Fields include, but are not limited to: general, medical and veterinary parasitology; morphology, including ultrastructure; parasite systematics, including entomology, acarology, helminthology and protistology, and molecular analyses; molecular biology and biochemistry; immunology of parasitic diseases; host-parasite relationships; ecology and life history of parasites; epidemiology; therapeutics; new diagnostic tools.

All papers in Parasite are published in English. Manuscripts should have a broad interest and must not have been published or submitted elsewhere. No limit is imposed on the length of manuscripts.

Parasite (open-access) continues Parasite (print and online editions, 1994-2012) and Annales de Parasitologie Humaine et Comparée (1923-1993) and is the official journal of the Société Française de Parasitologie. 